\title{
STUDY OF A LOOP HEAT PIPE USING NEUTRON RADIOGRAPHY
}

John M. Cimbala, Jack S. Brenizer, Jr., Abel Po-Ya Chuang, and Shane Hanna The Pennsylvania State University, Dept. of Mechanical and Nuclear Engineering

C. Thomas Conroy, A. A. El-Ganayni, and David R. Riley Bechtel Bettis, Inc., Bettis Atomic Power Laboratory

DE-AC11-98PN38206

\section{NOTICE}

This report was prepared as an account of work sponsored by the United States Government. Neither the United States, nor the United States Department of Energy, nor any of their employees, nor any of their contractors, subcontractors, or their employees, makes any warranty, express or implied, or assumes any legal liability or responsibility for the accuracy, completeness or usefulness of any information, apparatus, product or process disclosed, or represents that its use would not infringe privately owned rights. 


\title{
STUDY OF A LOOP HEAT PIPE USING NEUTRON RADIOGRAPHY
}

\author{
John M. Cimbala, Jack S. Brenizer, Jr., Abel Po-Ya Chuang, and Shane Hanna
}

The Pennsylvania State University, Dept. of Mech. and Nuclear Engineering

\author{
C. Thomas Conroy, A. A. El-Ganayni, and David R. Riley \\ Bechtel Bettis, Inc., Bettis Atomic Power Laboratory
}

\begin{abstract}
An explanation is given of what a loop heat pipe (LHP) is, and how it works. It is then shown that neutron imaging (both real time neutron radioscopy and single exposure neutron radiography) is an effective experimental tool for the study of LHPs. Specifically, neutron imaging has helped to identify and correct a cooling water distribution problem in the condenser, and has enabled visualization of two-phase flow (liquid and vapor) in various components of the LHP. In addition, partial wick dry-out, a phenomenon of great importance in the effective operation of LHPs, has been identified with neutron imaging. It is anticipated that neutron radioscopy and radiography will greatly contribute to our understanding of LHP operation, and will lead to improvement of LHP modeling and design.
\end{abstract}

\section{Introduction}

A heat pipe is a device used to transfer heat in a highly efficient and effective manner, with no moving parts. The effective coefficient of thermal conductivity of a heat pipe can be orders of magnitude higher than that of highly conductive solid materials, such as copper (Faghri, 1995). Heat pipes are used in various applications, such as spacecraft cooling, heat exchangers, electronic equipment cooling, deicing of roadways, and permafrost stabilization. A loop heat pipe (LHP) is a particular kind of heat pipe in which the evaporator and condenser components are separated, with the working fluid transported between the two components via tubing or pipes. LHPs can transport heat efficiently over some distance and at various gravitational orientations. A schematic diagram of an LHP is shown in Figure 1.

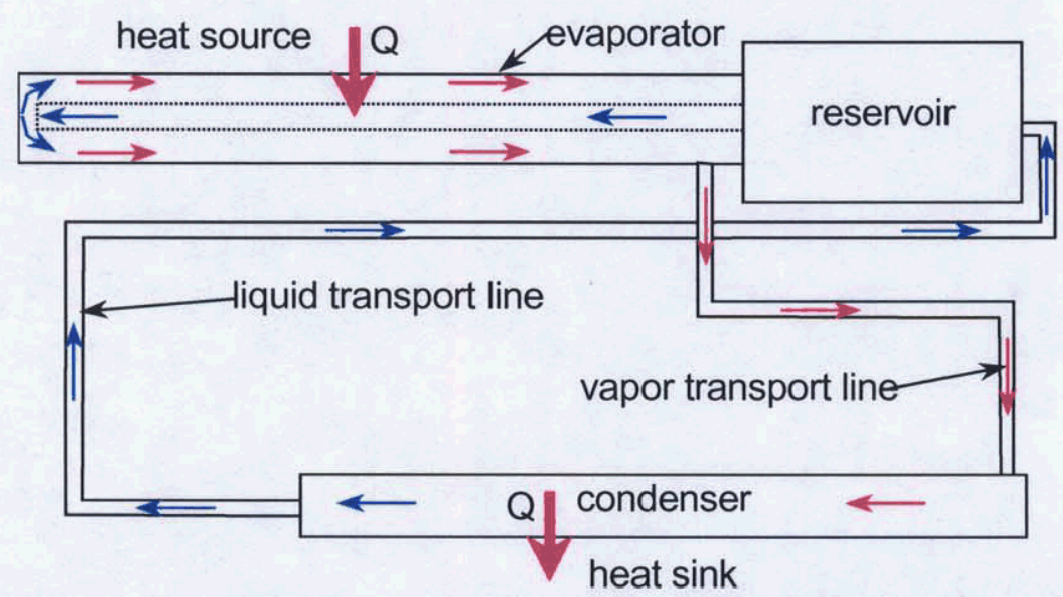

Figure 1. Schematic diagram of a loop heat pipe. Arrows indicate direction of flow of the working fluid.

The LHP absorbs heat and vaporizes the working liquid in the evaporator. Vapor is then transported to the cold region through the vapor transport line. In the condenser, the vapor is condensed to liquid, and slightly subcooled; the liquid is transported back to the hot region through the liquid transport line. A reservoir of working fluid is connected to the evaporator to prevent internal wick dry-out and to collect any vapor formed in the interior 
region of the evaporator. Since the working fluid is in equilibrium between liquid and vapor, it remains at nearly constant temperature, i.e. saturation temperature, throughout the entire loop. A detailed schematic view of the evaporator region is shown in Figure 2.

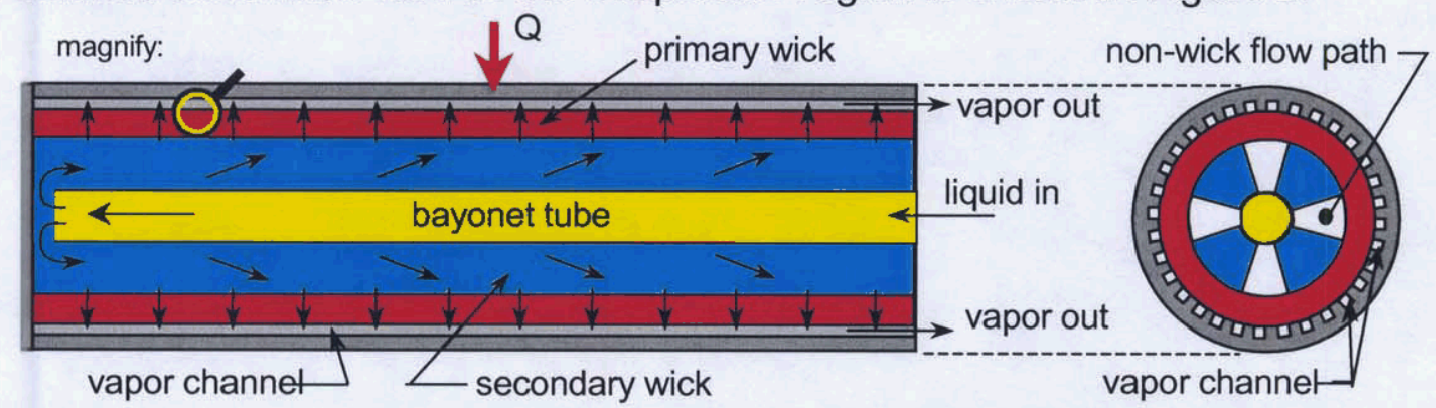

Figure 2. Schematic diagram of the evaporator section of a loop heat pipe (not to scale). Arrows indicate direction of flow of the working fluid.

Liquid enters the evaporator from the reservoir through the bayonet tube. The liquid turns around at the end of the evaporator and wets the secondary wick, whose primary purpose is to supply liquid to the primary wick. Liquid is drawn through small capillary channels or pores in the primary wick where it evaporates at menisci, whose shapes are determined by surface tension of the liquid, pore size of the primary wick, and contact angle at the liquidvapor interface. A magnified view of the interface region is shown in Figure 3.

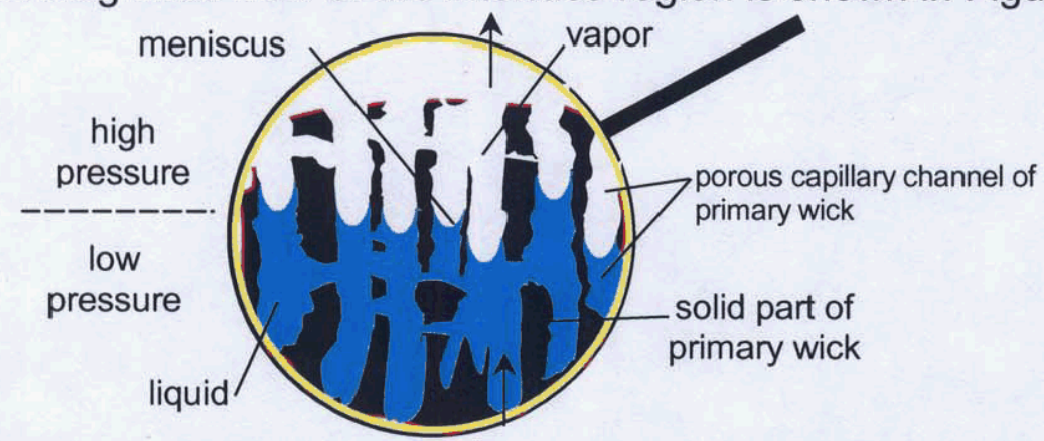

Figure 3. Magnified view of the primary wick, showing the interface between liquid and vapor, and the low and high-pressure regions.

The pressure rise across the menisci is sufficient to maintain flow of vapor and liquid through the entire LHP system. In other words, surface tension acts as a "pump" to drive the flow, with pressure being highest in the vapor region just above the menisci, and lowest in the liquid region just below the menisci. The vapor flows along the outer portion of the evaporator through small axial grooves called vapor channels, which combine and direct the vapor into the vapor transport line. Pressure continuously decays as the fluid travels through the vapor transport line, condenser, liquid transport line, bayonet, secondary wick, and primary wick.

The focus of the present work is to use flow visualization results from neutron radiography to further our understanding of LHP operation. The heat pipe under study here uses ammonia as the working fluid, an electrical heater strip to supply energy, and chilled water for the condenser. A photograph of the LHP used in the present experiments is shown in Figure 4. 


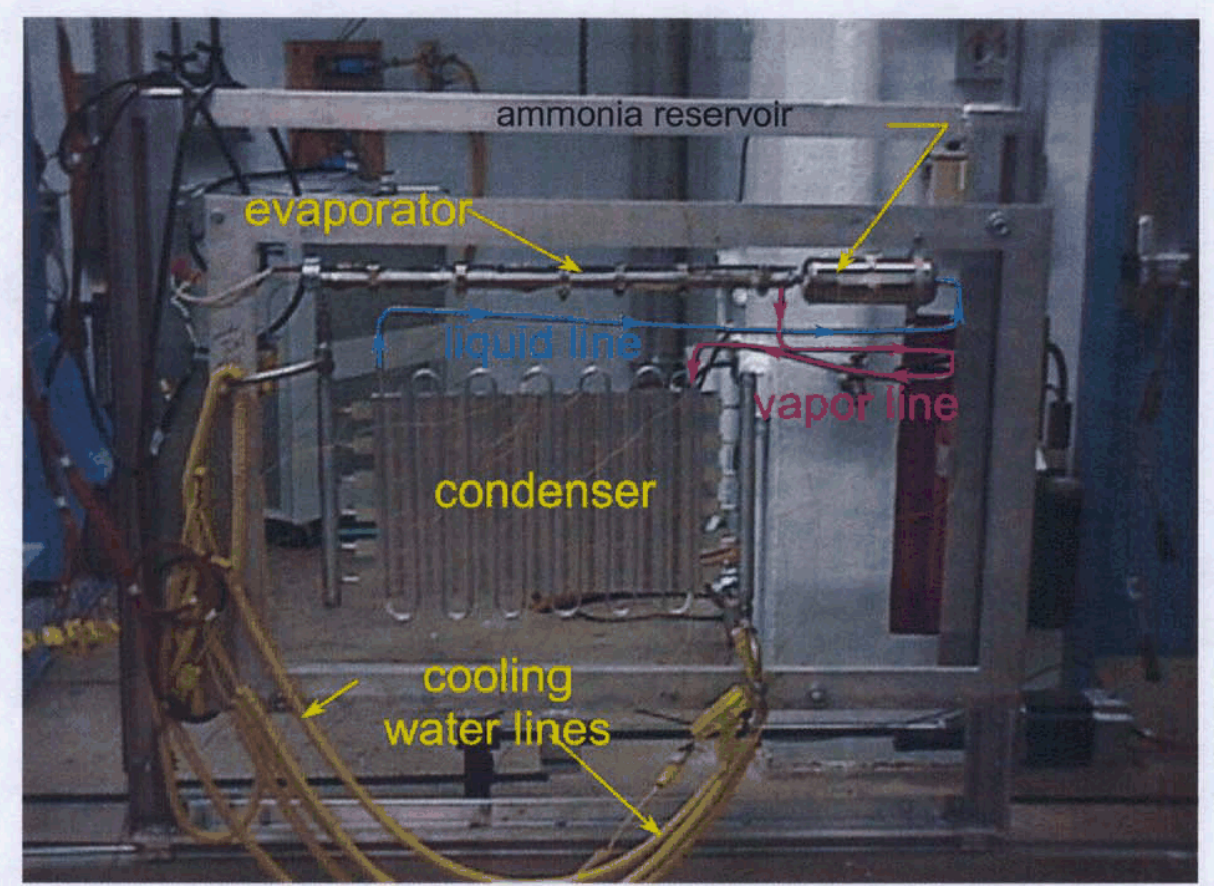

Figure 4. Photograph of the ammonia LHP used in the present experiments. The liquid line and vapor lines are highlighted for clarity.

The liquid and vapor transport lines have been annotated and highlighted in Figure 4 for clarity. The condenser is a cross-counterflow heat exchanger in which the ammonia lines run vertically and the water lines run horizontally. The cooling water lines are also annotated in Figure 4. The cooling water enters an inlet plenum from which the water is distributed to the six evenly spaced cooling water tubes. The LHP is instrumented with over twenty type K thermocouples.

Neutron radiography and radioscopy are employed in order to see through the aluminum casing of the LHP and to visualize the working ammonia flow within. Neutron imaging is ideal for this experiment since the fluids (ammonia and water) have high neutron attenuation, while the shell of the heat pipe (aluminum) is nearly transparent to thermal neutrons. Liquids and vapors can also be easily distinguished since liquids inside the LHP appear dark on the images, while vapors, due to their lower density, appear much lighter. The neutron beam facility at the Breazeale Nuclear Reactor, The Pennsylvania State University, is utilized for these experiments. This facility is an ASTM E 544 Category 1 facility with a tangential collimator powered by a $1 \mathrm{MW}$ TRIGA research reactor. A schematic diagram of the facility is shown in Figure 5. 


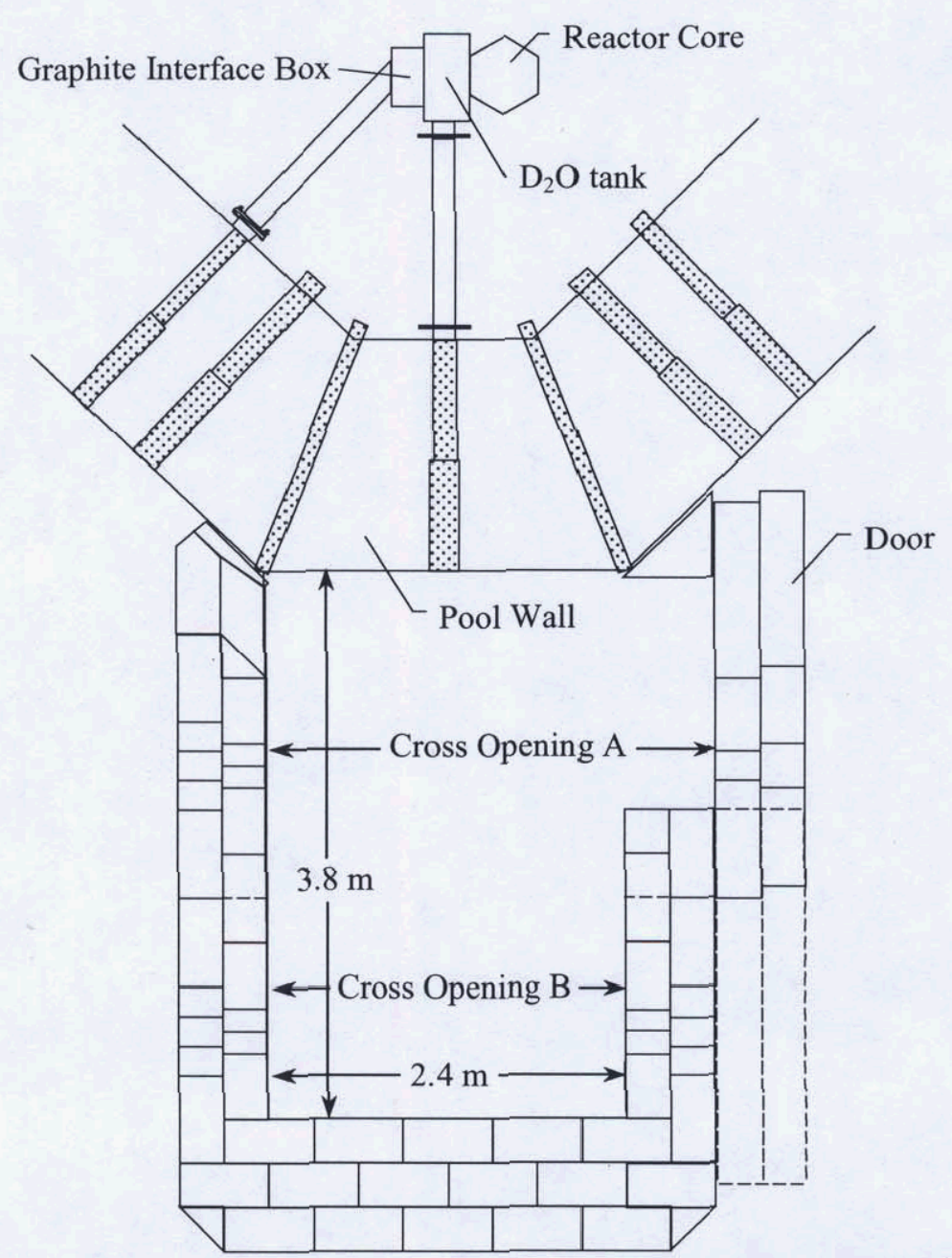

Figure 5. Schematic diagram of the neutron beam lab at the Penn State Breazeale Nuclear Reactor.

The neutron beam has an ASTM E $803 \mathrm{~L} / \mathrm{D}$ ratio of 115 , is 9.0 inches $(0.23 \mathrm{~m})$ in diameter, and has a neutron-to-gamma ratio of $3.1 \times 10^{6}\left(\mathrm{n} / \mathrm{cm}^{2}\right) / \mathrm{mR}$. The neutron-imaging laboratory is $2.4 \times 3.8-\mathrm{m}$ well-shielded working area. A 9-inch Thompson tube and 2-inch LiXi tube are available for radioscopy, along with image processing and storage equipment. Modeling the fluid flow, heat transfer, and thermodynamics of an LHP is difficult; there are phase changes (condensation and evaporation), capillary and surface tension effects, flow through porous media, gravitational effects, and heat transfer through solids, liquids, and porous media.

\section{Results}

Several key issues have been identified by neutron radiography and radioscopy, as listed and discussed below.

Gravitational effects - Operation of the LHP is sensitive to orientation with respect to gravity. An unexpected gravitational effect was also revealed by neutron radioscopy, namely a plumbing problem in the condenser. It was discovered that the cooling water did not always fill the condenser pipes. Figure 6 shows a neutron radioscopic image of the condenser cooling water inlet plenum filled with water at $1.0 \mathrm{gpm}$ flow rate. The horizontal pipes are the 
water pipes. The left vertical pipe is the inlet water plenum and the other vertical pipes are the ammonia loops. Note that the plenum is completely filled under these conditions.

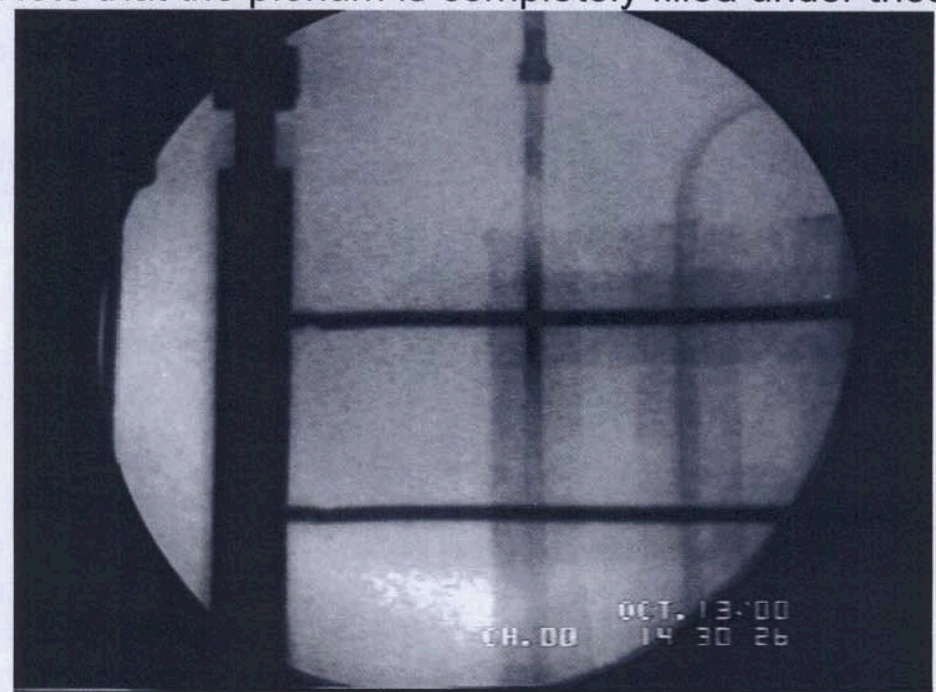

Figure 6. Neutron radioscopic image of the loop heat pipe condenser showing fully filled cooling water tubes. Water flow rate $=1.0 \mathrm{gpm}$.

Figure 7 shows the same view, but with the cooling water flowing at a lower rate $(0.41 \mathrm{gpm})$. Note that the water level in the plenum has fallen below the second water cooling tube in the condenser, eliminating cooling from the top two cooling lines. Some air bubbles are seen in the lower tube as well.

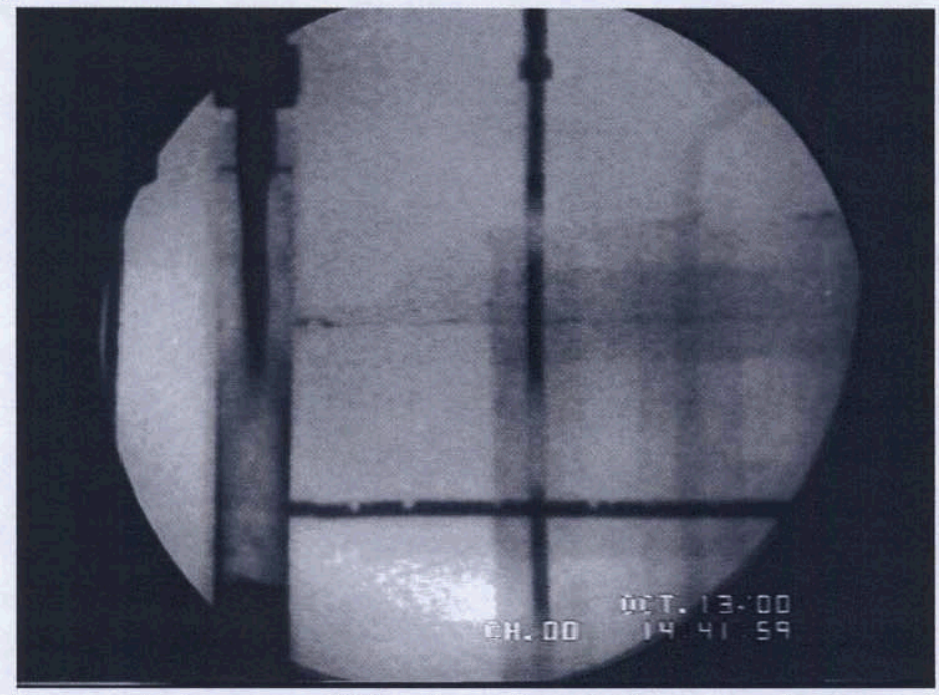

Figure 7. Neutron radioscopic image of the loop heat pipe condenser showing partially filled cooling water tubes. Water flow rate $=0.41 \mathrm{gpm}$.

Since these radioscopic images were taken, the plumbing has been modified to ensure that the cooling water always fills the cooling water tubes in the condenser.

Reverse flow - The flow of the working fluid is sometimes opposite to the normal flow direction. This is a transient phenomenon, only observed when the heater is turned off. The authors surmise that with no heat input, natural convection and radiation cause heat transfer from the evaporator to the ambient air, reversing the flow. As the unit cools, a point is 
reached where no flow is observed. Once this occurs, the evaporator cools only by convective losses.

Two-phase flow - Most LHP models treat the flow in the vapor line as pure vapor, and the flow in the liquid line as pure liquid. While this was found to be true for steady-state operation with cooling water chiller temperatures below $20^{\circ} \mathrm{C}$, neutron radioscopy revealed that during transient periods (after adjustment of the heater power or the sink temperature), and at higher chiller temperatures, the flow in both the vapor line and the liquid line is two-phase rather than single phase. As shown in Figure 8, slugs of vapor are sometimes observed in the liquid line; similarly, slugs of liquid are sometimes observed in the vapor line. When viewing the neutron radioscopy images in real time or by video recording, these slugs can be seen to move along the transport lines.

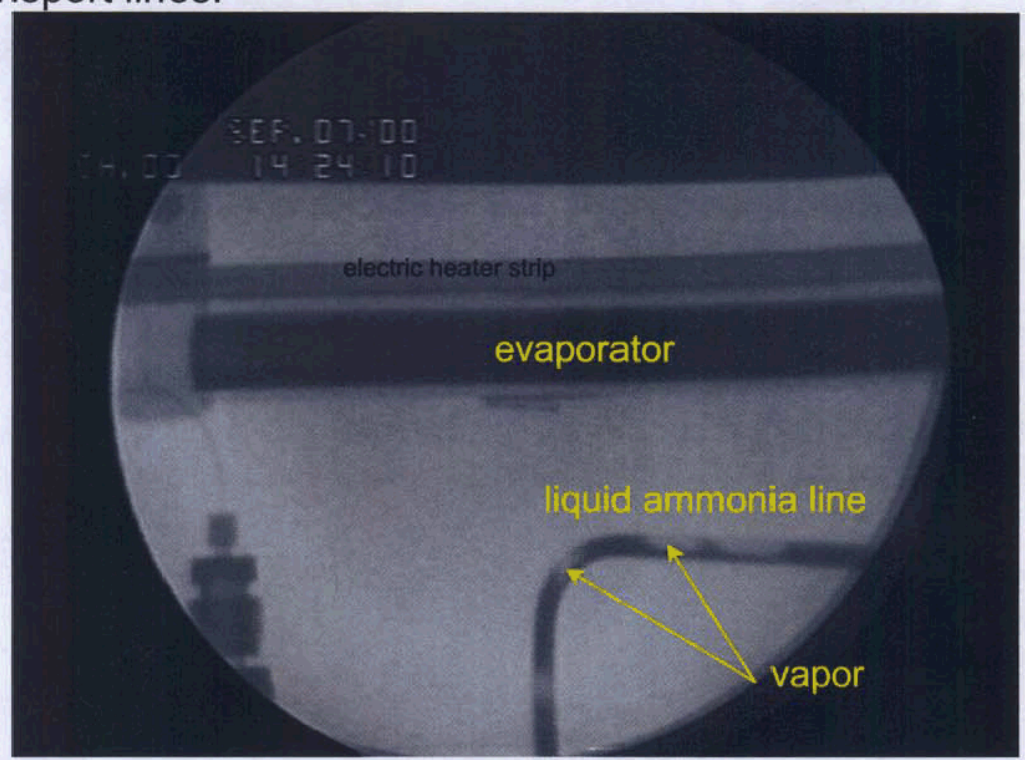

Figure 8. Neutron radioscopic image of the liquid ammonia transport line, revealing slugs of vaporous ammonia moving with the flow of liquid ammonia.

Transient effects - The LHP can be run in two modes; the evaporator held at constant temperature or constant heat supply to the evaporator. For the constant temperature mode, the strip heater is cycled on and off by a feedback controller. It was discovered that when the heating strip is cycled off, evaporation of the liquid immediately ceases since heat is being removed rather than added; this leads to reverse flow as discussed above. A periodic operating cycle results, with a period of several minutes. For the constant heat supply mode, the strip heater is on constantly, and no such periodic phenomenon is observed.

Partial wick dry-out - As mentioned previously, heat is supplied to the evaporator casing by a flat electric heater strip held in place by clamps. Neutron radiography (see Figure 9) revealed that heat is conducted to the primary wick more effectively in regions of the evaporator which are encompassed by a clamp. 


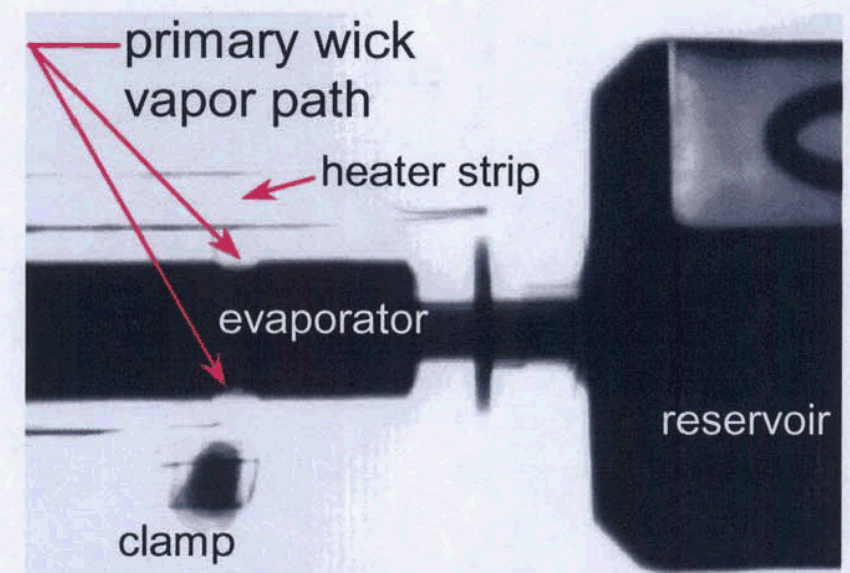

Figure 9. Neutron radiograph of the reservoir and evaporator regions. Vapor grooves near the end of the primary wick are visible during power operation.

Details of the primary wick can readily be seen in Figure 9. The notches near the end of the evaporator provide a flow path for the vapor to pass from the vapor channels in the evaporator casing to the vapor transport line (see Figure 2). When the LHP is shut down and cold, these notches fill with liquid and are not visible from the neutron radiographic images. As power is increased, vapor fills the notches and they become apparent. This result indicates that under certain conditions, partial wick dry-out may be visualized by neutron radiography. Primary wick dry-out significantly limits the performance of an LHP; these results show that further neutron radiography experiments should be able to reveal not only the location of wick dry-out, but also the extent of dry-out. Such results, coupled with thermocouple and flow rate measurements, will be useful to improve our understanding of LHP operation.

Condenser effects - At steady-state operating conditions, the vapor/liquid boundary of the ammonia in the condenser is observed to consistently occur near the condenser exit, regardless of cooling water temperature. As the cooling water temperature is lowered, the operating saturation temperature of the entire loop decreases correspondingly. Similar results were found when the power to the strip heater was decreased. In other words, the LHP self-regulates the flow rate, saturation temperature, and pressure rise across menisci such that the working fluid condenses at the end of the condenser, regardless of heat transfer conditions at either the hot region or cold region of the device (within the operating limits).

\section{Conclusions}

In summary, neutron radiography and radioscopy flow visualizations of a loop heat pipe are contributing greatly to our understanding of LHP operation. In addition, they have led to some modifications that improve performance.

\section{References}

Faghri, A. (1995) Heat Pipe Science and Technology, Taylor \& Francis, Washington, DC. 